\title{
Effects of Home-based Incentive Spirometry on FEV1, FVC, 6-MWT, Control Status and Quality of Life of Asthma Patients
}

\author{
Ula Firdausi ${ }^{a^{*}}$ Imam Subadi ${ }^{\text {b }}$, Dewi Poerwandari ${ }^{*}$, Muhammad Amin $^{\text {d, }}$ \\ Soenarnatalina Melaniani ${ }^{\mathrm{e}}$ \\ a,c* Corresponding author: ula.firdausi-2017@fk.unair.ac.id ; dewi.poerwandari@fk.unair.ac.id \\ ${ }^{a}$ Residence of Physical Medicine and Rehabilitation Department, Faculty of Medicine, Airlangga University, Dr. Soetomo General \\ Academic Hospital, Surabaya, Indonesia \\ Email: ula.firdausi-2017@ fk.unair.ac.id \\ ${ }^{\mathrm{b}}$ Associate Professor of Physical Medicine and RehabilitationDepartment, Faculty of Medicine, Airlangga University, Dr. Soetomo \\ General Academic Hospital, Surabaya, Indonesia \\ ${ }^{c}$ Medical Staff of Physical Medicine and Rehabilitation Department, Faculty of Medicine, Airlangga University, Dr. Soetomo General \\ Academic Hospital, Surabaya, Indonesia \\ Email: dewi.poerwandari@fk.unair.ac.id \\ Professor of Pulmonology and Respiration Medicine Department, Faculty of Medicine, Airlangga University, Dr. Soetomo General \\ Academic Hospital, Surabaya, Indonesia \\ ${ }^{\mathrm{e}}$ Associate Professor of Department of Biostatistic and Population Study, Faculty of Public Health, Airlangga University, Surabaya, \\ Indonesia
}

\begin{abstract}
Rehabilitation management of Asthma patient, including breathing retraining that could be using incentive spirometry as biofeedback tool for patient when doing breathing exercise. The purpose of the research is to prove effect of home-based incentive spirometry (flow based) on FEV1, FVC, 6-MWT, asthma control status (ACT) and Quality of life (SGRQ) and spirometry test of asthma patient. This experimental study with Randomized Pre-test and Post-test Controlled Group design conducted at Dr Soetomo General Academic Hospital.

A total of 16 asthma patients aged 18-40 years were randomly and evenly divided into two groups. An exercise program using Incentive Spirometry (flow based) was given to the intervention group, whereas the control group doing diaphragmatic breathing exercises. Both workouts were performed at home for four weeks with frequency five times per day, each session has ten repetitions. Results indicates that exercise with home-based incentive spirometry (flow based) showed improvements in FVC parameters (p-value 0.009) large effect size (1.25), 6 MWT distance (p-value 0.005) large effect size (1.40); and activity score SGRQ (p-value 0.041) large effect size (0.8). Giving 4 weeks of home-based exercise with Incentive Spirometry-(flow-based) improves FVC, 6-MWT distance, and activity score of quality of life (SGRQ) in asthmatic patient.
\end{abstract}

Keywords: home-based Incentive Spirometry (flow based), asthma, FEV1, FVC, 6MWT, ACT, SGRQ.

\section{Introduction}

Asthma is one of ten major disease which causes morbidity and mortality in Indonesia, also made a great burden in the world, with the incidence 4.5 percent which is 4.6 percent in women and 4.4 percent in man (Kemenkes RI, 2014). In asthma there is hyperventilation marked by low arterial PaCO2 and respiratory alkalosis (Courtney, 2017), due to hypertonicity of the respiratory muscles (Ritz et al., 2015), a tendency to pulmonary hyperinflation and impaired in thoracic breathing, irregular, paradoxal, and excessive sighing. Increased tone and activity of the inspiratory 
muscles at the end of expiration increases lung inflation which changes the work pattern of the respiratory muscles to be shorter and weaker. This causes the loss of the appositional zone of the diaphragm, decreases inspiratory strength, and will increase the recruitment of accessory muscles of respiration in the neck and thorax (Decramer, 1997).

Asthma management attempts to improve and preserve quality of life so that patients can go about their daily lives without difficulty (Kepmenkes, 2008; GINA, 2019). This is accomplished by providing both pharmaceutical and non-pharmacological management, such as exercise. Breathing exercises for asthma patients are designed to normalized breathing patterns (breathing retraining), improve respiratory muscle strength and endurance, and improve chest wall flexibility and posture (Thomas and Bruton, 2014). The evidence on the advantages of breathing exercises for asthmatic patients is still equivocal, despite their widespread use (O Connor et al., 2015).

The technique of performing diaphragmatic breathing through a device with visual feedback based on the volume and flow of inspired air is known as Incentive Spirometry (Tyson, 2015). Incentive spirometry is similar to continuous maximal inspiration in that it is intended to simulate natural breathing and urge the patient to take deeper breaths.

This procedure reduces intrapleural pressure, expands the lungs, and improves gas exchange (AARC, 2011). Incentive spirometry is widely used as a prophylaxis for pulmonary complications in abdominal surgery (Tyson, 2015), Chronic Obstructive Pulmonary Disease (COPD) (Hoseini, 2016), and restrictive lung disease due to diaphragm or respiratory muscle dysfunction, such as in patients with spinal cord injuries. (SCI) (Mantri B, 2017) and as a breathing exercise aid for asthma patients at home (Mantri B, 2017).

Comparing with deep breathing exercises only (without support equipment), one of the advantages of Incentive Spirometry is that it is easy to monitor independently by trained patients, therefore it does not always require supervision (AACR, 2011). The goal of this study was to see how administering Incentive Spirometry as a breathing exercise assistance at home affected lung function metrics (FEV1 and FVC), functional capacity tested at 6-MWT, and asthma patients' quality of life.

\section{Materials and Methods}

This is an experimental study using Randomized Pretest and Postest Controlled Group Design. A total of 16 asthma patients aged 18-40 years were randomly and evenly divided into two groups at Dr. Soetomo Surabaya's Asthma/COPD Polyclinic. Inclusion criteria were those who have been diagnosed with asthma and are controls at the Asthma Polyclinic and who have received instructions on their asthma treatment regimen for at least a month before starting the study, aged 18-40 years old, willing to follow the study protocol, and are able to understand the exercise procedure. We exclude subjects who had exacerbation within 24 hours prior to the test; breastfeeding or pregnancy; another pulmonary disease (tuberculosis, lung cancer, pneumonia, interstitial lung disease, pneumothoraks, bronkiektasis, bloody cough); another chronic comorbidity (heart disease, liver disease, kidney disease, diabetes mellitus, SLE, Rheumatoid Arthritis), any forms of cancer (Osteosarcoma, glioblastoma, breast, colon/rectum, ovary, melanoma maligna, prostate hyperthrophy). We drop out the subject if they skip the program for more than 7 days or more than 20 sessions during the periods; add another structured breathing exercise program; move to out of study coverage area; and at any kind of reason choose to stop following the study.

Before the trial, the subject conducted a physical examination, were informed about the study, and completed an informed consent form. The subject was then given basic information, asked to fill out questionnaires to assess asthma control status (ACT) and quality of life (SGRQ), and had 6-MWT and Spirometry tests done on them. The subjects were then randomly assigned to one of two research groups: An exercise program using Incentive Spirometry-(flow-based) was given to the intervention group, whereas the control group did diaphragmatic breathing exercises without the use of any instruments. For four weeks, both workouts were performed at home five times per day, each with ten repetitions. Every day, each subject completed the exercises according to what was taught at home, as indicated by the completion of an exercise monitoring card signed by a witness. Once a week, the subjects were contacted, reminded, and retaught the exercises. Patients were asked to complete the 
questionnaire again at the conclusion of the fourth week to assess their asthma control status, quality of life (SGRQ), 6-MWT, and spirometry tests. The results are collected, and statistical analysis is performed. The findings of the analysis were thoroughly examined in order to draw inferences from them.

\section{Results and Discussion}

This study involved 19 patients who visited Asthma/COPD Pulmonary Polyclinic at Dr. Soetomo general academic hospital in Surabaya. For four weeks, research volunteers were randomly assigned to one of two groups: 10 persons in the intervention group and 9 people in the control group. Two subjects from the intervention group and one from the control group were removed from the study. One participant in the intervention group claimed that after following the exercise for two days withdrew from the trial due to chest discomfort; one other person was expelled for not being able to complete the exercise as scheduled. One participant in the control group said that she quit the study because his job environment had increased his activity, causing her to have frequent exacerbations ( 2 weeks early in the study of repeated exacerbations), and he moved outside the study's scope (outside the island). Six men and ten women were collected at the end of the study, divided into two groups of eight people each. This number still meets the required number of research subjects for each group, which is six individuals.

The Shapiro-Wilk test was performed to determine the normality of the research subjects' fundamental features. All data were normally distributed, and an independent parametric T-Test test was conducted across the two groups, with all initial parameters being equal (there was no difference between the two groups). Basic Characteristic of the subjects describe in table 1 and 2.

The results of this study revealed that no changes in all measures occurred before and after a 4-week homebased diaphragmatic breathing exercise. FEV1 (p-value 0.248), FVC (p-value 0.248), 6-MWT (p-value 0.115), ACT score (p-value 0.858), total score SGRQ (p-value 0.056), symptom score SGRQ (p-value 0.237), activity score SGRQ (p-value 0.366), and impact score SGRQ (p-value 0.366). (p-value 0.056).

Changes in asthma control status were assessed using the Asthma Control Test (ACT) questionnaire. According to the GINA recommendation, changes in asthma control status should be monitored monthly using the ACT questionnaire to measure the effect of medication on asthma control. This finding contradicts a study conducted by Grammatopapulou et al. (2012) on breathing exercise in asthmatics, which found that after one month of exercise, asthma control status (ACT) improved significantly.

The findings of this study differ from those of Chung et al. (2021) and Majewski et al. (2015), who found that after 8 and 12 weeks of exercise, both breathing exercises with the Inspiratory Muscle Trainer device and breathing exercises without additional aids could improve the functional status of asthmatic patients, with no difference between the two interventions.

Exercises that improve the position of the diaphragm as it rises and falls during inspiration and expiration are known as diaphragmatic breathing. Deeper, slower breaths ensure that air is distributed evenly throughout the lungs. Slow breathing fills essential capacities, while holding the breath for 3-5 seconds allows the lungs to expand fully, opening the alveoli and increasing surfactant production. Diaphragmatic breathing exercises will also lessen the activity of accessory muscles of respiration, allowing for more typical breathing patterns and less breathing work (Grams et al., 2012). Diaphragmatic breathing exercises, according to Tahir et al. (1973), can enhance basal ventilation. Diaphragmatic breathing exercises, according to Weber and colleagues (1993), enhance tidal volume and facilitate fluid evacuation. Tactile stimulation above the lower rib cage, as well as verbal instructions, increased diaphragmatic movement during exercise, according to Blaney and Sawyer (1997). Diaphragmatic breathing exercises, according to Manzano et al. (2008), can enhance lung mechanics and, as a result, boost FVC. The lack of change before and after exercise could be related to the patient's inability to maintain good exercise technique when conducting the exercises at home alone. 
Tabel 1. Subject characteristics

\begin{tabular}{|c|c|c|c|}
\hline Profile & Control Group (n=8) & $\begin{array}{c}\text { Intervention Group } \\
(\mathrm{n}=8)\end{array}$ & p-value \\
\hline \multicolumn{4}{|l|}{ Age (Years) } \\
\hline Mean \pm Standard Deviation & $28,50 \pm 7,57$ & $27 \pm 7,38$ & 0,695 \\
\hline Min - Max & $19-\overline{4} 0$ & $1 \overline{8}-40$ & \\
\hline \multicolumn{4}{|l|}{ BMI $\left(\mathrm{kg} / \mathrm{m}^{2}\right)$} \\
\hline Mean \pm Standard Deviation & $26,80 \pm 4,94$ & $25,26 \pm 6,04$ & 0,586 \\
\hline Min - Max & $19.04-32.03$ & $17.15-34.96$ & \\
\hline \multicolumn{4}{|l|}{ Asthma Duration (years) } \\
\hline Mean \pm Standard Deviation & $10,75 \pm 6,86$ & $15,00 \pm 10,47$ & 0,353 \\
\hline $\operatorname{Min}-\operatorname{Max}$ & $2-19$ & $1-33$ & \\
\hline \multicolumn{4}{|l|}{ FEV1 $(\mathrm{ml} / \mathrm{s})$} \\
\hline Mean \pm Standard Deviation & $2478,75 \pm 590$ & $2167,50 \pm 465,97$ & 0,261 \\
\hline Min - Max & $1830-3 \overline{3} 60$ & $1500-2710$ & \\
\hline \multicolumn{4}{|l|}{$\mathrm{FVC}(\mathrm{ml})$} \\
\hline Mean \pm Standard Deviation & $3041,25+748,91$ & $2708,75+527,18$ & 0,322 \\
\hline Min - Max & $2190-4190$ & $2130-3530$ & \\
\hline \multicolumn{4}{|l|}{ 6-MWT (m) } \\
\hline Mean \pm Standard Deviation & $347,56 \pm 111,74$ & $398,25 \pm 106,48$ & 0,369 \\
\hline $\operatorname{Min}-\operatorname{Max}$ & $207-\overline{5} 17.5$ & $189-540$ & \\
\hline \multicolumn{4}{|l|}{ ACT Score } \\
\hline Mean \pm Standard Deviation & $17,75 \pm 2,5$ & $15,75 \pm 4,06$ & 0,258 \\
\hline Well controlled (25) & 0 & 0 & \\
\hline Partially controlled (20-24) & 2 & 0 & \\
\hline Uncontrolled $(\leq 19)$ & 6 & 8 & \\
\hline \multicolumn{4}{|l|}{ Total SGRQ Score } \\
\hline Mean \pm Standard Deviation & $1594,10 \pm 802,60$ & $2041,60 \pm 982.36$ & 0,335 \\
\hline Min - Max & $157-26 \overline{65} 7.70$ & $381.20-3389.70$ & \\
\hline \multicolumn{4}{|l|}{ Symptom Score (SGRQ) } \\
\hline Mean \pm Standard Deviation & $279,26 \pm 148,5$ & $378,15 \pm 102,3$ & 0,143 \\
\hline Min - Max & $86.8-505.40$ & $219.40-525.40$ & \\
\hline \multicolumn{4}{|l|}{ Activity score (SGRQ) } \\
\hline Mean \pm Standard Deviation & $642,23 \pm 308,05$ & $665.1 \pm 391.47$ & 0,898 \\
\hline Min - Max & $0-985.80$ & $0-1134.90$ & \\
\hline \multicolumn{4}{|l|}{ Impact score (SGRQ) } \\
\hline Mean \pm Standard Deviation & $672.60+381.40$ & $998.26+535.22$ & 0,183 \\
\hline $\operatorname{Min}-$ Max & $34.60-1229.60$ & $161.80-1845-90$ & \\
\hline
\end{tabular}

Patients were told about the study orally at the start, written down on the monitoring card they took home, and shown with the trainer's help. Patients are urged to meet face-to-face once a week, either at the hospital or at their homes, to check probable side effects, exercise issues, and to remind them of proper technique. The patient also fills out the exercise column, which is confirmed by a member of the patient's family who has been designated as a home exercise supervisor in advance. The patient sits erect in an upright sitting position with the right hand on the epigastric and the left hand on the front chest during the workout. Movement occurs when inspiration is anticipated. The findings of this study can be used to provide an overview and assessment that the diaphragmatic breathing exercise technique with hands on the chest and belly, which is intended to be used as a home exercise program for asthma patients, is ineffective.

Exercise with home-based incentive spirometry-(flow-based) for 4 weeks improved the FVC parameter (pvalue 0.009 ) with a large effect size (1.25), the distance before and after exercise (p-value 0.005$)$ with a large effect size (1.40), and the activity score SGRQ (p-value 0.041 ) with a large effect size (1.40). (0.8).

The effect of strengthening inspiratory muscles on FEV1 and FVC in asthmatic patients has been debated in previous studies. This study's findings are like those of Chung et al. (2021), who compared inspiratory muscle strengthening exercises with weights on an Inspiratory Muscle Trainer (IMT) in asthma patients for 12 weeks 2 sessions per week, finding differences in FVC increase in the intervention group but failing to meet the MCID. 
Chung et al. (2021) found that both groups improved their inspiratory muscular strength, as measured by an increase in maximal inspiratory pressure (PI Max), particularly the exercise group with BMI. According to the reference, the BMI exercise is identical to the Incentive Spirometry exercise in terms of respiratory phase, loading, and training goal, which is to improve the inspiratory muscles. The study found that FVC values improved significantly, which, while not clinically significant, could indicate an increase in inspiratory muscle strength

Table 2. Additional Profile of the Subjects

\begin{tabular}{ll}
\hline Profile & Total \\
\hline Gender & \\
Male & $6(37.5 \%)$ \\
Female & $10(62.5 \%)$ \\
Allergic History & $13(81.25 \%)$ \\
Yes & $3(18.75 \%)$ \\
No & \\
Source of allergic & $9(56.25 \%)$ \\
Dust (including fur) & $8(50 \%)$ \\
Foods and drug & $3(18.75 \%)$ \\
Cold weather & \\
Occupation & $2(12.5 \%)$ \\
Housewife & $4(25 \%)$ \\
College students & $1(6.25 \%)$ \\
Student & $2(12.5 \%)$ \\
Worker & $7(43.75 \%)$ \\
Self-employed & \\
\end{tabular}

The 6-MWT gap between the intervention group and (flow-based) improved from an average of $347.56+111.74$ to $452.825+100.281$. (p-value 0.005). According to the findings of Chung et al. (2021), breathing exercises with the Inspiratory Muscle Trainer device can improve the functional status of asthmatic patients within 6 MWT. Majewski et al. (2015) also suggested that breathing exercises with the Inspiratory Muscle Trainer device can improve the functional status of asthmatic patients.

Incentive Spirometry device is based on the volume of inspiration (volume-oriented) or airflow (airfloworiented) (Flow- oriented). The Incentive Spirometry-(flow-based) system consists of three chambers, each with a sphere. The ball will be elevated in its chambers if the patient applies sub-atmospheric pressure on it. Lifting the first ball requires a $600 \mathrm{~mL} / \mathrm{s}$ inspiratory flow, lifting the first and second balls requires $900 \mathrm{~mL} / \mathrm{s}$, and lifting the complete ball requires $1200 \mathrm{~mL} / \mathrm{s}$. The volume-oriented incentive spirometer is a collection of devices with a capacity of up to $4000 \mathrm{~mL}$ and a one-way valve that prevents expiration. The amount of inspiratory volume and flow that can lead the subject to inhale gently is indicated. Incentive spirometry is used to help patients inflate their lungs to their maximum capacity and maintain that expansion. This maximum lung expansion is supposed to be able to open the collapsed alveoli, preventing the atelectasis from being overcome. During inspiration, maximum lung expansion raises transpulmonary pressure. Reinflation of alveoli keeps them inflated during expiration, enhancing the lung's functional capacity (Ho et al., 2000).

The findings of this study contradict those of Nikmah et al. (2014), who found that utilizing Incentive Spirometry considerably improved lung function (FEV1), otherwise was similar result for measures of functional status (6-MWT distance), and quality of life in asthmatic patients (SGRQ). There are some discrepancies with this research. First, a volume-based incentive spirometer was used in the study. Second, a longer period of exercise is required ( 8 weeks) and the subject was asthmatic patients with allergic bronchial asthma. 
Table 3. Inter and Intra-Group Analysis

\begin{tabular}{|c|c|c|c|c|}
\hline Variable & & $\begin{array}{c}\text { Control/ } \\
\text { Diaphragmatic } \\
\text { breathing }(\mathbf{n}=8) \\
(\text { Mean+ SD) }\end{array}$ & $\begin{array}{c}\text { Intervention/ } \\
\text { Incentive Spirometry } \\
(\mathbf{n}=8)(\text { Mean+ SD) }\end{array}$ & $\begin{array}{l}\text { p-value (T- test } \\
\text { Independent) }\end{array}$ \\
\hline \multirow[t]{5}{*}{ FEV1 (ml) } & Pre-test & $2167.50+465.97$ & $2478.75+590.7$ & 0,261 \\
\hline & Post-test & $2061.25 \pm 383.60$ & $2620 \pm \overline{6} 40.2$ & 0,053 \\
\hline & Paired t-test & $0, \overline{24} 8$ & 0,192 & \\
\hline & Difference Pre and Post test & $106,25 \pm 283,44$ & $-141,25 \pm 276,94$ & 0,076 \\
\hline & $\%$ & $3, \overline{7} 4$ & $-6,13$ & \\
\hline \multirow{5}{*}{$\begin{array}{l}\text { FVC } \\
(\mathrm{ml})\end{array}$} & Pre-test & $2708,75 \pm 527,18$ & $3041,25 \pm 748,91$ & 0,322 \\
\hline & Post-test & $2690.00 \pm 471.835$ & $3331.25 \pm 658.297$ & $0,042 *$ \\
\hline & Paired t-test & 0,927 & $0,009^{*}$ & \\
\hline & Difference Pre and Post test & $18,75+556,29$ & $-290 \pm 231,82$ & 0,169 \\
\hline & $\%$ & $-1,50$ & $-10,86$ & \\
\hline \multirow{5}{*}{$\begin{array}{l}\text { 6-MWT } \\
(\mathbf{m})\end{array}$} & Pre-test & $398,25 \pm 106,48$ & $347,56 \pm 111,74$ & 0,369 \\
\hline & Post-test & $438.750 \pm 52.0913$ & $452.825 \pm 100.2817$ & 0,730 \\
\hline & Paired t-test & $0, \overline{1} 15$ & $0, \overline{00} 5^{*}$ & \\
\hline & Difference Pre and Post test & $-40,5 \pm 71,91$ & $-105,26 \pm 74,72$ & 0,099 \\
\hline & $\%$ & $-17,5$ & $-37,6$ & \\
\hline \multirow{5}{*}{ ACT Score } & Pre-test & $15,75 \pm 4,06$ & $17,75 \pm 2,5$ & 0,258 \\
\hline & Post-test & $17.00 \pm 5.071$ & $17.75 \pm 3.694$ & 0,740 \\
\hline & Paired t-test & 0,858 & 1,000 & \\
\hline & Difference Pre and Post test & $-1,25 \pm 6,73$ & $0 \pm 2,72$ & 0,634 \\
\hline & $\%$ & $-20,9$ & 0,07 & \\
\hline Total & Pre-test & $2041,60 \pm 982.36$ & $1594,10 \pm 802,60$ & 0,335 \\
\hline SGRQ & Post-test & $1725.32 \pm 881.98$ & $1243.92 \pm 863.92$ & 0,289 \\
\hline \multirow[t]{3}{*}{ Score } & Paired t-test & $0,0 \overline{5} 6$ & $0,0 \overline{9} 4$ & \\
\hline & Difference Pre and Post test & $316,27+390,89$ & $350,17+511,22$ & 0,884 \\
\hline & $\%$ & 20,7 & 28,17 & \\
\hline \multirow{5}{*}{$\begin{array}{l}\text { Symptom } \\
\text { Score } \\
\text { (SGRQ) }\end{array}$} & Pre-test & $378,15 \pm 102,3$ & $279,26 \pm 148,5$ & 0,303 \\
\hline & Post-test & $313,7 \pm 154,63$ & $235,80 \pm 153,43$ & 0,329 \\
\hline & Paired t-test & 0,252 & 0,304 & \\
\hline & Difference Pre and Post test & $64,65 \pm 140,87$ & $43,46 \pm 110,7$ & 0,745 \\
\hline & $\%$ & $1 \overline{5}, 34$ & 21,78 & \\
\hline \multirow{5}{*}{$\begin{array}{l}\text { Activity } \\
\text { score } \\
\text { (SGRQ) }\end{array}$} & Pre-test & $665.1 \pm 391.47$ & $642,23 \pm 308,05$ & 0,898 \\
\hline & Post-test & $600.62 \pm 403.82$ & $415,31 \pm 277.39$ & 0,303 \\
\hline & Paired t-test & $0, \overline{3} 66$ & $0, \overline{0} 1^{*} *$ & \\
\hline & Difference Pre and Post test & $64,56 \pm 198,1$ & $226,92 \pm 256,56$ & 0,172 \\
\hline & $\%$ & 10,61 & 32,66 & \\
\hline \multirow{5}{*}{$\begin{array}{l}\text { Impact } \\
\text { score } \\
\text { (SGRQ) }\end{array}$} & Pre-test & $998.26 \pm 535.22$ & $672.60 \pm 381.40$ & 0,183 \\
\hline & Post-test & $811.00 \pm 448.80$ & $592.81 \pm 489.40$ & 0,368 \\
\hline & Paired t-test & 0,056 & 0,422 & \\
\hline & Difference Pre and Post test & $187,26 \pm 231,8$ & $79,78 \pm 264,7$ & 0,402 \\
\hline & $\%$ & 24,98 & 27,47 & \\
\hline
\end{tabular}

Improvements in diaphragmatic muscle strength may be the mechanism of improvement in lung function (FVC), functional status (6-MWT), and quality of life (SGRQ) identified in the intervention group of this study. Deep and slow breathing exercises with Incentive Spirometry are performed with an instrument that provides visual feedback. This feedback could help patients monitor their exercise skills at home and provide more motivation than unassisted diaphragmatic workouts. Flow-based and volume-based incentive spirometers have different physiological effects. Flow-oriented incentive spirometry encourages increased respiratory effort and upper-chest muscular performance. The Coach-2 gadget (volume-oriented), requires less breathing effort and 
enhances diaphragmatic activity. When comparing the effects of diaphragmatic breathing, flow, and volumebased Incentive Spirometry on diaphragmatic excursions and lung function in post-laparoscopic patients, Alaparthi and his team (2016) found that diaphragmatic breathing and volume-based Incentive Spirometry exercises significantly prevent lung function decline as measured by FVC. To date, there are no studies that compare the effectiveness of utilizing flow-based and volume-based Incentive Spirometry for asthmatic patients.

There were four minor adverse events recorded during the research, and no major adverse events. In the intervention group, one moderate adverse event was observed, while three incidents were reported in the control group. One occurrence in the intervention group was the start of chest tightness, which made the participant fearful of an exacerbation. Finally, the participant withdrew from the research. A few days later, a follow-up exam revealed that the soreness had subsided and had returned to normal. Exacerbations rose in the first control group of subjects because of increased activity at work. This exacerbation can be treated with a medication that the patient already has on hand. Subjects finally dropped out of the study because they strayed too far from its parameters. Another individual complained of exhaustion; it was later discovered that the subject had performed the exercise more frequently and for longer than the required number of repetitions. Re-education was given, and the subject followed the study's instructions, resulting in the patient's condition improving once more. After exercise, another person in the control group complained of heartburn and nausea. One subject of diaphragmatic breathing exercise pressing the abdomen strongly in the hope of providing greater resistance to the decrease in the diaphragm. The patient improved after being re-educated on the technical training and continued the exercise program until it was completed. Neither group experienced any major adverse events during the research.

Incentive Spirometry-(flow-based) is the most widely utilized complement to respiratory rehabilitation programs in the hospital where the study was conducted, and it is available in pharmacies and hospitals at a reasonable price.

This study has several limitations including: 1) The research technique is not blinded. The same researchers randomized the participants, observed the exercise program's progress, and collected data following the exercise time. 2) Outside of the exercise program, physical activity and allergen exposure of research subjects could not be controlled, even though participants had been instructed not to participate in other structured physical exercise programs and to prevent allergy exposure during the study. There are still variables beyond the researcher's control that can affect the patient's control status and quality of life. The family witnesses the patient's compliance with the exercise regimen, which is recorded on a monitoring card filled out by the patient himself. Video calls, phone conversations, and house visits were also used to monitor the situation. Aside from that, this research method has disadvantages in terms of ensuring that the patient performs the activity correctly and obediently. 3) After the patient had exercised for a longer period of time, no monitoring or follow-up was done, therefore the additional improvement effects that came after a longer period of exercise were not documented. 4) Other metrics that directly reflect muscular strength improvement, such as PI max and/or biofeedback, were not measured in this study.

\section{Conclusion}

We may conclude from the findings of this study that providing asthmatics with home-based exercise using Incentive Spirometry-(flow-based) influences raising FVC (p 0.009), 6-MWT distance (p 0.005), and activity score of quality of life (SGRQ) (p 0.041).

\section{Acknowledgments}

We thank Development and Research Department of Dr. Soetomo General Academic Hospital, which has provided financial assistance for this research through the Penelitian Unggulan grant program.

\section{References}

AARC. 2011. Restrepo, Ruben D; Richard Weunstein; Wittnebel, Leo; Tracy, Michael. AARC Clinical Practice Guidelines Incentive Spirometry: 2011. Respiratory Care: Oct 20111. Vol. 56. No10.

Agostini, P. and Singh, S., 2009. Incentive Spirometry following thoracic surgery: what should we be doing?. Physiotherapy, 95(2), pp.76-82. 
Alaparthi, G.K., Augustine, A.J., Anand, R. and Mahale, A., 2016. Comparison of diaphragmatic breathing exercise, volume and flow Incentive Spirometry, on diaphragm excursion and pulmonary function in patients undergoing laparoscopic surgery: a randomized controlled trial. Minimally invasive surgery, 2016.

Arden-Close, E., Teasdale, E., Tonkin-Crine, S., Pitre, N., Stafford-Watson, M., Gibson, D., Bruton, A., Thomas, M. and Yardley, L., 2013. Patients' perceptions of the potential of breathing training for asthma: a qualitative study. Primary Care Respiratory Journal, 22(4), pp.449-453.

American Thoracic Society Documents. An Official American Thoracic Society/European Respiratory Society Statement: Guidelines for the six-minute walking test. 2002. Am J Respir Crit Care Med Vol 166. Pp 111-117, 2002 DOI: 10.1164/rccm.166/1/111. Internet address: www.atsjournals.org

Barnes PJ. Patophysiology of asthma. European Respiratory Monograph 2003; 23: 84-113.

Banzett, R.B., Dempsey, J.A., O'DONNELL, D.E. and Wamboldt, M.Z., 2000. Symptom perception and respiratory sensation in asthma. American journal of respiratory and critical care medicine, 162(3), pp.1178-1182.

Blaney, F. and T. Sawyer. 1997. "Sonographic measurement of diaphragmatic motion after upper abdominal surgery: a comparison of three breathing manoeuvres," Physiotherapy Theory and Practice, vol. 13, no. 3, pp. 207-215, 1997

Bonini, M.; Di Paolo, M.; Bagnasco, D.; Baiardini, I.; Braido, F.; Caminati, M.; Carpagnano, E.; Contoli, M.; Corsico, A.; Del Giacco, S. 2020. Minimal clinically important difference for asthma endpoints: An expert consensus report. Eur. Respir. Rev. $2020,29,190137$.

Bruton, A., Kirby, S., Arden-Close, E., Taylor, L., Webley, F., George, S., Yardley, L., Price, D., Moore, M., Little, P. and Holgate, S., 2013. The BREATHE study: breathing retraining for asthma - trial of home exercises. A protocol summary of a randomised controlled trial. Primary Care Respiratory Journal, 22(2), pp.S1-S7.

Cairo, J.M., 2017. Mosby's Respiratory Care Equipment-E-Book. Elsevier Health Sciences.

Coe R. 2002. It's the effect size, stupid: what "effect size", is and why it is important. Paper presented at the 2002 Annual Conference of the British Educational Research Association, University of Exeter, Exeter, Devon, England, September 12-14, 2002. http://www.leeds.ac.uk/educol/documents/00002182.htm. Accessed March 23, 2012.

Courtney, Rosalba. 2017. Breathing training for dysfunctional breathing in asthma: taking a multidimensional aproach. ERJ Open Res 2017; 3; 0065-2017 (http://doi.org/1183/23120541.00065-2017).

Decramer, M., 1997. Hyperinflation and respiratory muscle interaction. European Respiratory Journal, 10(4), pp.934-941.

De Troyer A, Estenne M. Functional anatomy of the respiratory muscles. Clin Chest Med 1988; 9: 175-193.

El-Marakby, A.A., Darwiesh, A., Anwar, E., Mostafa, A., El-Gendy, S.R., Gaowgzeh, R.A. and Jad, A., 2013. Aerobic exercise training and Incentive Spirometry can control postoperative pulmonary complications after laparoscopic cholecystectomy. Middle East Journal of Scientific Research, 13(4), pp.459-463.

Gallucci, M., Carbonara, P., Pacilli, A.M.G., di Palmo, E., Ricci, G. and Nava, S., 2019. Use of symptoms scores, spirometry, and other pulmonary function testing for asthma monitoring. Frontiers in pediatrics, 7, p.54.

Global Strategy for Asthma Management and Prevention. 2019. Avaliable from: www.ginaasthma.org.

Grams, S.T; Ono, L.M; Noronha, M. A.; Schivinski, C. I. S. and E. Paulin. 2012. "Breathing exercises in upper abdominal surgery: a Systematic Review and meta-analysis," Brazilian Journal of Physical Therapy, vol. 16, no. 5, pp. 345-353.

Grammatopoulou, E.P., Skordilis, E.K., Stavrou, N., Myrianthefs, P., Karteroliotis, K., Baltopoulos, G. and Koutsouki, D., 2011. The effect of physiotherapy-based breathing retraining on asthma control. Journal of Asthma, 48(6), pp.593-601.

Ho, SC; Chiang, LL; Cheng, HF; Lin, HC; Sheng, DF; Kuo, HP; Lin HC. 2000 The effect of Incentive Spirometry on chest expansion and breathing work in patients with chronic obstructive airway diseases: comparison of two methods. Chang Gung Med J. Feb;23(2):73-9.

Holgate Stephen T; Sally Wenzel;Dirkje S. Postma; Scott T. Weiss; Harald Renz; Peter D. Sly6. 2015. Asthma. Article number: 15025 doi:10.1038/nrdp.2015.25 Published online 10 September 2015

Holloway E, West RJ. Integrated breathing and relaxation training (Papworth Method) for adults with asthma in primary care: a randomised controlled trial. Thorax 2007; 62: 1039-1042

Hosseini, Seyed Hossein Ahmadi; Farzad, Marjan; Heydari, Abbas. 2016. Comparing the Effect of Resistive Inspiratory MuscleTraining and Incentive Spirometry on Respiratory Pattern of COPD patients. Evidence Based Care Journal, 6 (3): 45-54

Howell J. Behavioural breathlessness. Thorax 1990; 45: 287-292.

Izuhara, Y., Matsumoto, H., Nagasaki, T., Kanemitsu, Y., Murase, K., Ito, I., Oguma, T., Muro, S., Asai, K., Tabara, Y. and Takahashi, K., 2016. Mouth-breathing, another risk factor for asthma: the Nagahama Study. Allergy, 71(7), pp.1031-1036. 
Jack, S., Rossiter, H.B., Warburton, C.J. and Whipp, B.J., 2003. Relationship between behavioral influences and ventilatory control mechanisms in patients with idiopathic hyperventilation. Behav Modif, 27, pp.637-652.

Johns DP, Pierce R. The Measurement and Interpretation of Ventilatory Function in Comparison of Flow and Volume Incentive Spirometry on Pulmonary Function and Exercise Tolerance in Open Abdominal Surgery: A Randomized Clinical Trial. Journal of Clinical and Diagnostic Research. 2016 Jan, Vol-10(1): KC01-KC06. DOI: 10.7860/JCDR/2016/16164.7064

Kumar, A.S., Alaparthi, G.K., Augustine, A.J., Pazhyaottayil, Z.C., Ramakrishna, A. and Krishnakumar, S.K., 2016. Comparison of flow and volume Incentive Spirometry on pulmonary function and exercise tolerance in open abdominal surgery: a randomized clinical trial. Journal of clinical and diagnostic research: JCDR, 10(1), p.KC01.

Loftus PA, Wise SK. Epidemiology of asthma. Curr Opin Otolaryngol Head Neck Surg 2016; 24: $245-9$.

Lwanga, S.K., \& Lemeshow, S. 1991. Sample size determination in health studies: a practical manual. World Health Organization.

Meltzer, E.O., Busse, W.W., Wenzel, S.E., Belozeroff, V., Weng, H.H., Feng, J., Chon, Y., Chiou, C.F., Globe, D. and Lin, S.L., 2011. Use of the Asthma Control Questionnaire to predict future risk of asthma exacerbation. Journal of Allergy and Clinical Immunology, 127(1), pp.167-172.

Majewski, M., Dąbrowska, G., Pawik, M. and Rożek, K., 2015. Evaluation of a home-based pulmonary rehabilitation program for older females suffering from bronchial asthma. Advances in Clinical and Experimental Medicine, 24(6), pp.1079-1083.

Morales-Blanhir, J.E., Palafox Vidal, C.D., Rosas Romero, M.D.J., García Castro, M.M., Londoño Villegas, A. and Zamboni, M., 2011. Sixminute walk test: a valuable tool for assessing pulmonary impairment. Jornal brasileiro de pneumologia, 37, pp.110-117.

Muller N, Bryan A, Zamel N. Tonic inspiratory muscle activity as a cause of hyperinflation in asthma. J Appl Physiol 1981; 50: $279-282$.

Manzano, R.M.; De Carvalho, C. R. F.; Saraiva-Romanholo, B.M. and J. E. Vieira. 2008. "Chest physiotherapy during immediate postoperative period among patients undergoing upper abdominal surgery: Randomized clinical trial," Sao Paulo Medical Journal, vol. 126, no. 5, pp. 269-273, 2008.

Nelsen, Linda; Cockle, Sarah; Kimel, Miriam et al. 2016. Quantitative Validity of the Sgrq in Patients with Severe Asthma. J Allergy Clin Immunol. 2016.

Nikmah, Sitti Nurun; Purba, Ambrosius; Defi, Irma Ruslina D. 2014. Efektivitas Latihan Incentive Spirometry dengan Latihan Pernapasan Diafragma terhadap Fungsi Paru, Kapasitas Fungsional, dan Kualitas Hidup Penderita Asma Bronkial Alergi. MKB, Volume 46 No. 1, Maret 2014.

O'Donnell, D.E., Banzett, R.B., Carrieri-Kohlman, V., Casaburi, R., Davenport, P.W., Gandevia, S.C., Gelb, A.F., Mahler, D.A. and Webb, K.A., 2007. Pathophysiology of dyspnea in chronic obstructive pulmonary disease: a roundtable. Proceedings of the American Thoracic Society, 4(2), pp.145-168.

Parks MJ. The limits of breath holding. Sci Am 2012; 306: 74-79.

Prem, V., Sahoo, R.C. and Adhikari, P., 2013. Effect of diaphragmatic breathing exercise on quality of life in subjects with asthma: A systematic review. Physiotherapy theory and practice, 29(4), pp.271-277.

Reddel, H.K., Taylor, D.R., Bateman, E.D., Boulet, L.P., Boushey, H.A., Busse, W.W., Casale, T.B., Chanez, P., Enright, P.L., Gibson, P.G. and de Jongste, J.C., 2009. An official American Thoracic Society/European Respiratory Society statement: asthma control and exacerbations: standardizing endpoints for clinical asthma trials and clinical practice. American journal of respiratory and critical care medicine, 180(1), pp.59-99.

Rietveld, S. and Everaerd, W., 2000. Perceptions of asthma by adolescents at home. Chest, 117(2), pp.434-439. Ritz T, Meuret AE, Bhaskara L. 2013. Respiratory muscle tension as symptom generatorin individuals with high anxiety sensitivity. Psychosom Med 2013; 75: 187195.

Sastroasmoro S, Ismael S. 1995. Dasar-dasar metodologi penelitian klinis. Penyunting : Sastroasmoro, Ismael S. edisi 1. Binarupa Aksara Jakarta, 1995:1-278.

Shifren, A; Witt, C; Christie, C; Castro, M. 2012. Mechanisms of Remodeling in Asthmatic Airways. 2012;2012:15-7.

Slader, CA; Reddel, HK; Jenkins, CR; Armour, CL; Bosnic-Anticevich, SZ. 2006. Complementary and alternative medicine use in asthma: who is using what? Respirology 2006; 11:373-387.

Tahir, A.H; George, R. B.; Weill, H.; Adriani, J. 1973. "Effects of abdominal surgery upon diaphragmatic function and regional ventilation," International Surgery, vol. 58, no. 5, pp. 337-340

Weber, B. A. and J. Prayar. 1993. "Physiotherapy skills: techniques and adjuncts," in Physiotherapy for Respiratory and Cardiac Problems, B. A. Webber andJ.Prayar, Eds. pp. 113-171, Churchill Levingstone, Edinburgh, UK. 